The Relationship Between Demographic Factors and Marital Satisfaction of Couples Intended to Divorce Referred to Family Judicial Complex in Borujerd County

Fazlollah Ghofranipour

* Professor of Health Education Dept., School of Medical Sciences, Tarbiat Modares University, Tehran, Iran. (Corresponding Author) ghofranf@ modares.ac.ir

Farkhondeh Aminshokravi

Associated Professor of Health Education Dept., School of Medical Sciences, Tarbiat Modares University, Tehran, Iran.

\section{Roya Tarkashvand}

PhD Candidate in Health Education \& Health Promotion, Health Education Dept., School of Medical Sciences, Tarbiat Modares University, Tehran, Iran.

Roya.torkashvand@modares.ac.ir

Received: 11 April 2016

Accepted: 30 January 2016

DOI: 10.18869/acadpub.ihepsaj.5.1.43

\section{ABSTRACT}

Background and objective: Marital satisfaction is affected by many factors among which the safe and pleasurable marital relationships are the most important one. In Iran, marital satisfaction involves socio-cultural obstacles as well as the limiting policies which make research difficult. Therefore, adequate information is not available in the area. The aim of this research was to determine marital satisfaction level among the couples who intended to separate from each other and its association with some demographic factors.

Materials and methods: This descriptive-correlation study was conducted in 2015 through Black size Randomization among 130 couples intended to divorce referred to the family judicial complex in Borujerd County, Iran. ENRICH and demographic questionnaires were used for data collection and were analyzed through SPSS21.

Results: Marital satisfaction of $51 \%$ of women and $57 \%$ of men were low. The results also showed that there was a statistically significant association between marital satisfaction and the following factors: age difference of couples ( $p=$ $0.000)$, duration of married life $(p=0.048)$, education $(p=0.035)$ and income ( $p$ $=0.041)$ and age difference of women $(p=0.000)$, marital type $(p=0.839)$, education ( $p=0.045$ ), but there was no statistically significant association between marital satisfaction and other factors tested in this study.

Conclusion: According to the results, practical strategies to improve couple's awareness about marital satisfaction and its vital influences on marital satisfaction is recommended. Further studies are needed to be done in order to provide research-based information in this field.

Keywords: Demographic factors - Marital satisfaction, Divorce, Family Court, Borujerd.

Paper Type: Research Article.

- Citation (Vancouver): Ghofranipour F, Aminshokravi F, Tarkashvand R. The relationship between demographic factors and marital satisfaction of couples intended to divorce referred to family judicial complex in Borujerd County. Iran $J$ Health Educ Health Promot. Spring 2017;5(1): 43-50. [Persian]

- Citation (APA): Ghofranipour, F., Aminshokravi, F., \& Tarkashvand R. (Spring 2017). The relationship between demographic factors and marital satisfaction of couples intended to divorce referred to family judicial complex in Borujerd County. Iranian Journal of Health Education \& Health Promotion., 5(1), 43-50. [Persian] 
رابطه عوامل جمعيتشناسى با رضايت زناشويى زوجين متقاضى طلاق مراجعه كننده به مجتمع قضايى خانواده شهرستان بروجرد

\section{بكيله}

زمينه و هدف : رضايت زناشويى تحت تأثير عوامل مختلفى قرار دارد. داشتن روابط زناشويى رضايت بخانش

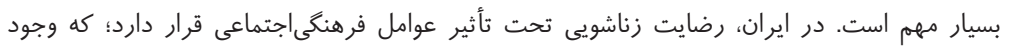

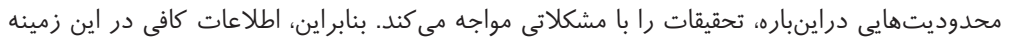

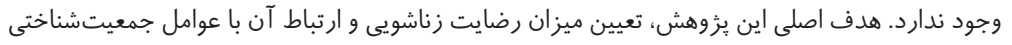

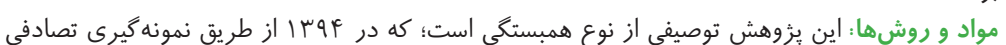

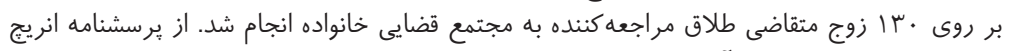

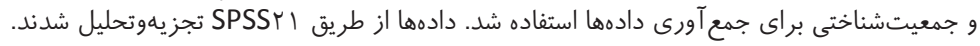

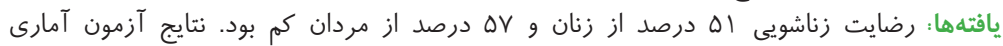

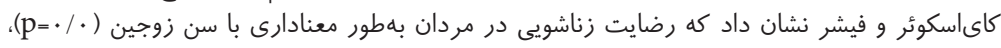

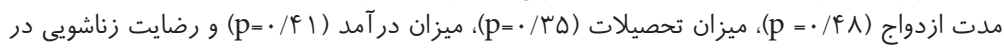

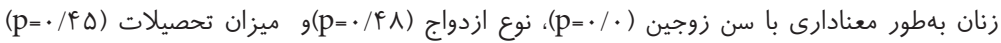

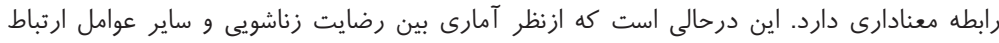

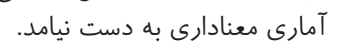

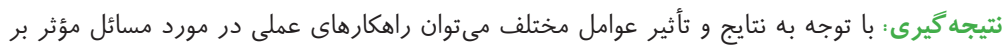

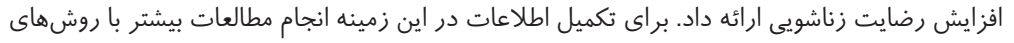
كتفاوت پيشنهاد مى شود.

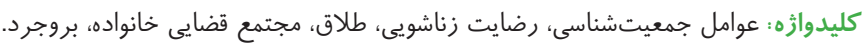

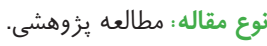

4 استناد (ونكوور): غفرانى يور ف، امينشكروى ف، تركاشوند ر. رابطه عوامل جمعيت شناسى با رضايت

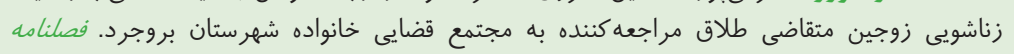

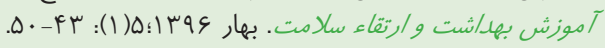

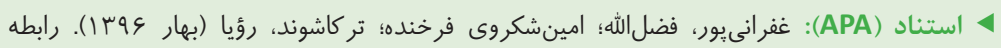

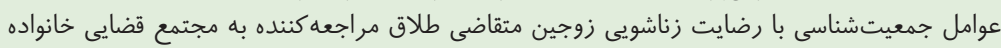

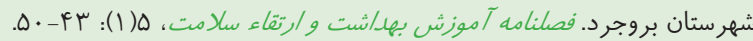
فضل الله غفر انى بور * قاستاد كروه آموزش بهداشت و وارتقاء سلامت،

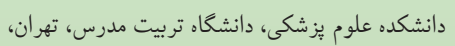
ghofranf@modares.ac.ir

$$
\text { فرخنده امين شكروى }
$$

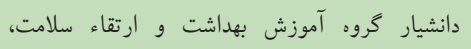

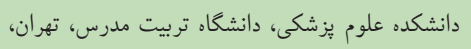
رؤيا تر كاشوند دانشجوى دكترى آموزش بهداشت و ارتقاء سلامت،

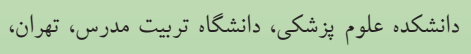

ايران.

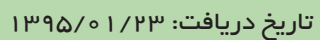

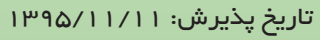


با هدف بررسى تأثير برنامه غنىسازى بر رابطه زوجين نشان داد كه • ه درصد علت شكست ازدواجها، نارضايتى جنسى زوجين

به نظر مىرسد يكى از متغيرهاى اثر گذار بر رضايت زناشويى

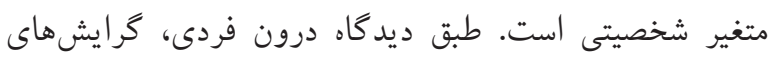

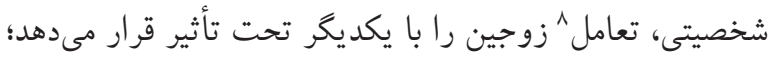
كه ميزان رضايت در اين تعاملات، اثر كلى بر رضايتمندى دارد(4). يك رابطه رضايتمند، مستلزم آن است كه زوجين ياد

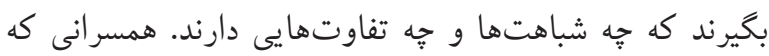

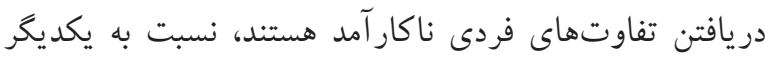
رضايتمندى كمترى دارند(V). آسيبها و تعارضهايى، "كه بين زوجين بهطور مداوم

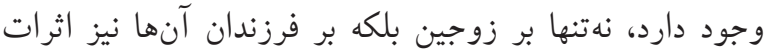

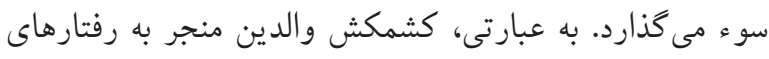

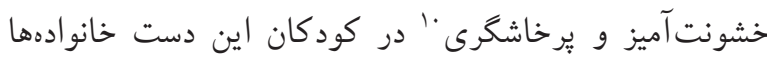
مىشود. هرجند درباره يِيشيُى از ناساز گارى زناشويى و طلاق مطالب زيادى آموختهشده است؛ اما هنوز در مراحل اوليه فهم جگگنكى كمى به زوجين براى داشتن يك ازدواج بادوام

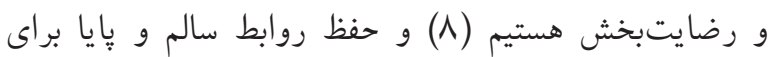
آنان نيز جالشزا است. يكى از دلايل اين مسئله، اين است كه عواملى كه رضايت زناشويى را تحت تأثير قرار مىدهد احتمالاً

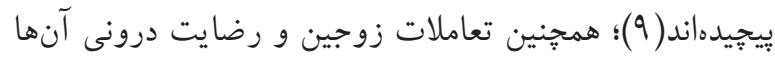
بر اين روابط بسيار تأثير كذار است ( • (1). آمار زياد طلاق نشان از نارضايتىهاى زناشويى دارد. (11). البته بسيارى از ازدواجهاى ناشاد و آشفته نيز وجود دارند؛ كه زوجين به دلايل گوناگون طلاق نمى گيرند و يكديكر را تحمل مى كنند. بهطور مثال، در استانهاى ايلام، كرمانشاه و همدان

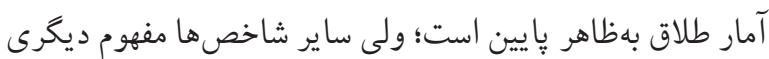

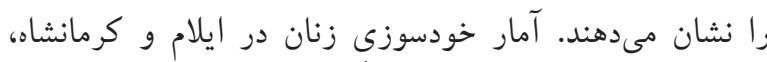

خانواده نخستين و منحصربهفردترين نهاد اجتماعى است؛ كه

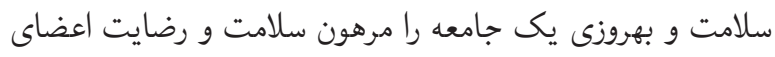

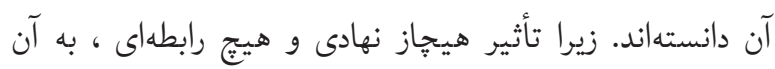

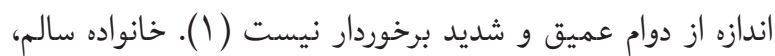
نظامى باز است كه اعضاى آن در عين داشتن روابط عاطفى' كرم، هويت فردى خود را حفظ مى كنند (Y). بديهى است كه تقريباً

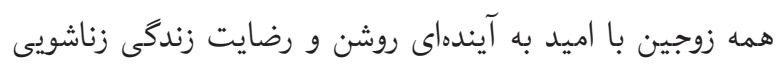

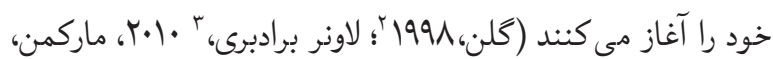

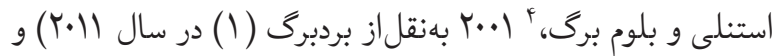

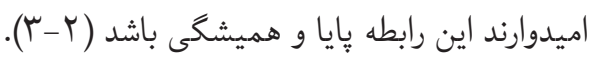
دستيابى به جامعه سالم بهطورقطع در گرو سلامت خانواده

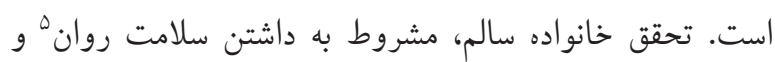

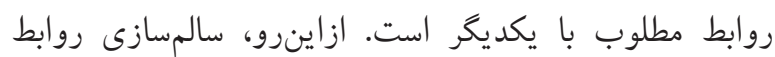

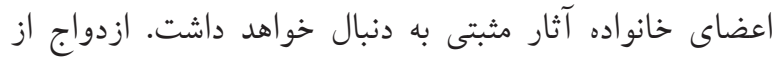
نخستين تعهدات عاطفى و قانونى افراد، ازجمله تصميمهاى مهم زندگى، به شمار مىرود. باوجود بيامدهاى ازدواج مناسب،

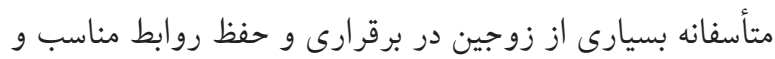
مؤثر با يكديكر با مشكلاتى مواجه هستند. از آنجايى كه تعاملات

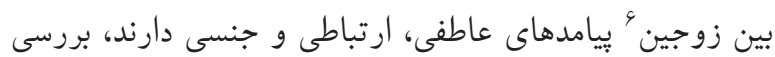
عوامل اثر كذار بر آن امرى ضرورى به نظر مى بـرسد (r).

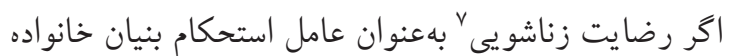
بهطور كامل بهوجود نيايد، مىتواند اثرات زيانبار جسمى و روانى

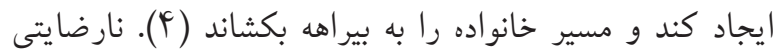

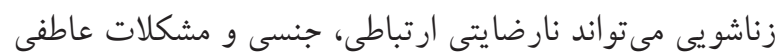

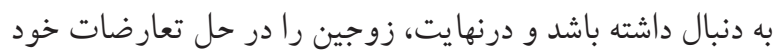

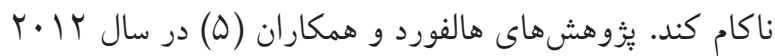

\section{Affective}

2. Glenn

3. Lovner \& Bradburg

4. Markman, Stanly \& Blumberg

5. Mental Health

6. couple

7. marital satisfaction 
با رضايت زناشويى رابطه دارد.

مو اد و روش ها

يُزوهش حاضر مطالعه توصيفى -همبستكى بود. جامعه يُّوهش

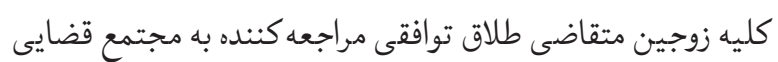

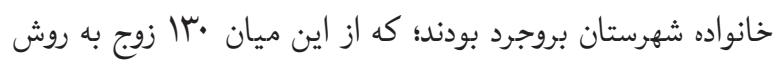

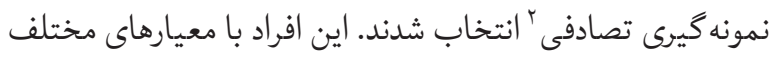
وارد يُووهش شدند: داوطلب بودن، متقاضى طلاق توافقى، نداشتن بيمارى روانى و مغزى و اولين بار طلاق كرفتن.

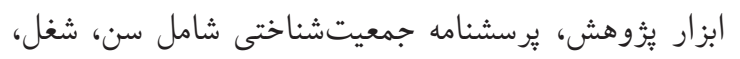

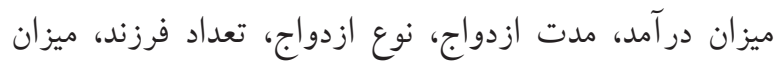

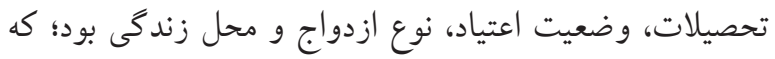

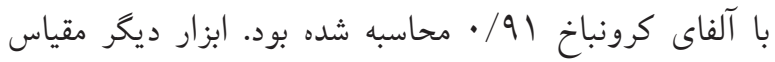

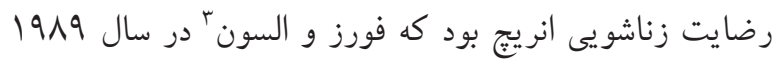

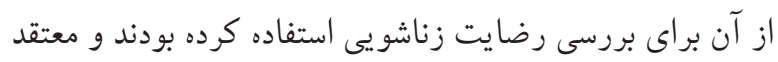
بودند كه اين مقياس نسبت به تغييراتى كه در خانواده به وجود رد رسي

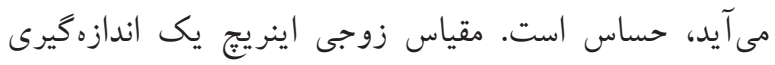

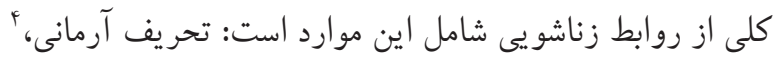

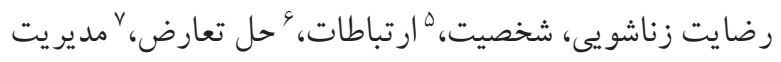

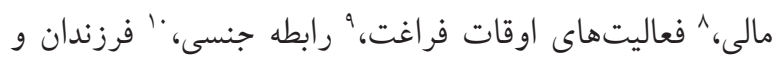

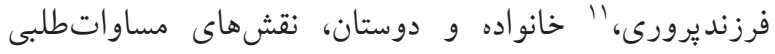

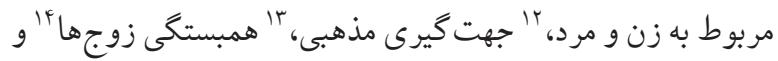

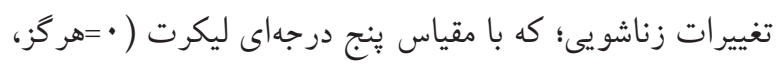

2. Black size randomization

3. Fowers \& Olson

4. idealistic distortion

5. personality

6. communication

7. conflict resolution

8. financial management

9. leisure activities

10. sexual relationship

11. children and parenting

12. equalitarian roles

13. religious orientation

14. marital cohesion
كه دردناكترين نوع خودكشى است، مىتواند نشانه فرياد

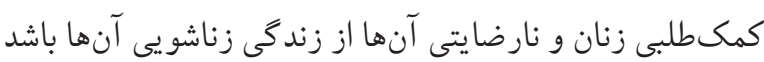

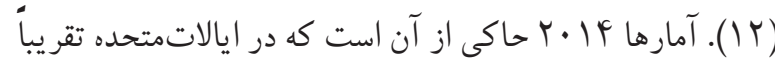
يكدوم تادوسوم ازدواجها به طلاق مىانجامد (1 (I).

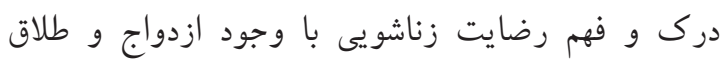

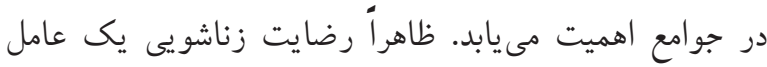
تعيين كننده مهم بهزيستى روانشناختى براى زوجين است. افراد داراى بهزيستى بهتر رفتارهاى رمانتيك بهترى را نشان

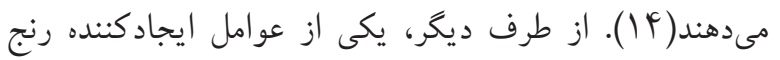

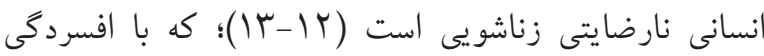

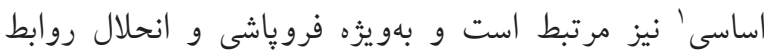
براى اعضاى خانو اده بسيار تخريبكننده است (0) (1). مطالعات نشان مىدهند كه داشتن يك رابطه سالم رضايتبخش متقابل

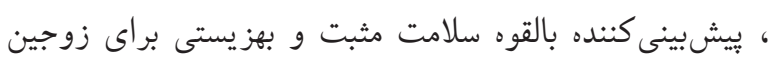

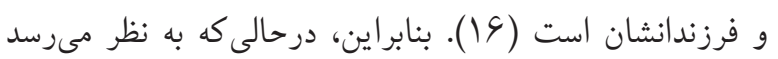

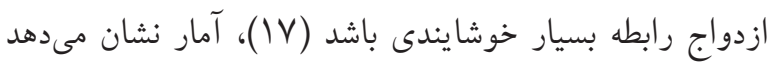

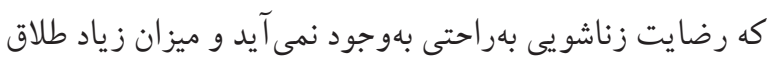

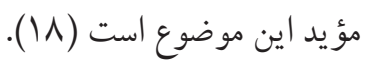

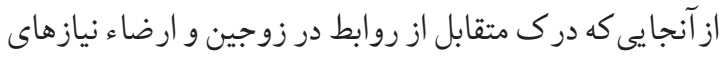

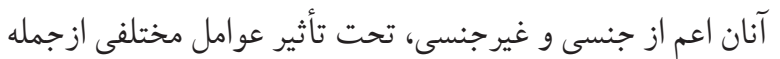

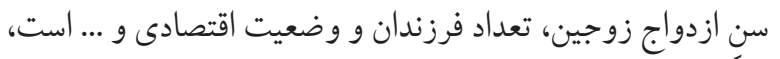
لذا برداختن به رابطه متقابل اين عوامل با رضايت زناشو تيى و تداوم

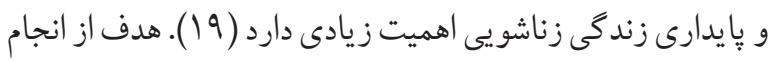
اين تحقيق بررسى رابطه عوامل جمعيتشناختى مثل سن ازدواج،

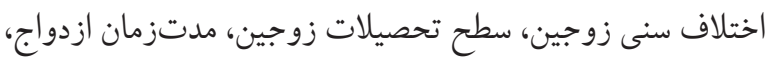

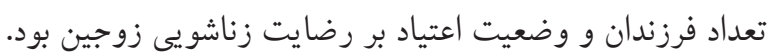

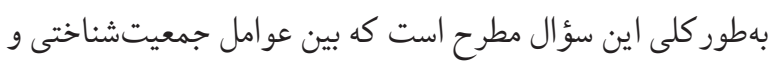

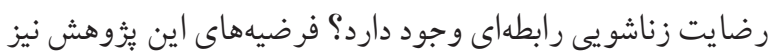

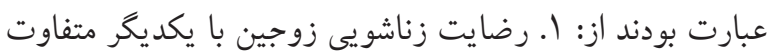

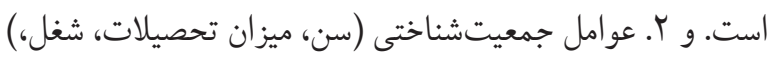




\begin{tabular}{|c|c|c|c|}
\hline مرد & زن & زوج & متغير \\
\hline & & $(\mid r, \Lambda) \backslash \Lambda$ & $. r-1$ \\
\hline & & $(r), \Delta) r \wedge$ & s-r \\
\hline & & $(r \cdot, \Delta) r V$ & $.10-9$ \\
\hline & & $(\mathrm{V}, \mathrm{V})) \cdot$ & +10 \\
\hline \multicolumn{4}{|c|}{ نحوه آشنايى براى ازدواج } \\
\hline & & $(19,9) r r$ & دوستان و آشنايان \\
\hline & & $(r \cdot, \Lambda) \uparrow$. & خانواده \\
\hline & & $(\Delta r, \Gamma) \& \Lambda$ & معرفى ديخران \\
\hline \multicolumn{4}{|c|}{ محل زندگى } \\
\hline & & $(\wedge 9, r) \backslash \backslash \varsigma$ & شهر \\
\hline & & $(1 \cdot, \Lambda) \mid F$ & ا روستا \\
\hline \multicolumn{4}{|c|}{ علت تقاضاى طلاق } \\
\hline & & $\left(r \Delta, F^{c}\right) \notin \varepsilon$ & مشكلات رفتارى \\
\hline & & $(19,9) r r$ & 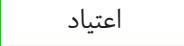 \\
\hline & & $(\zeta, r) \wedge$ & اقتصادى \\
\hline & & $(\zeta, \Gamma) \wedge$ & interfere \\
\hline & & $(\xi, \xi) \xi$ & بد ممانى \\
\hline & & $(r \xi, \xi) \mu r$ & بيمارى مقاربتى \\
\hline & & $(r, 1) F$ & بيمارى روانتنى \\
\hline & & $(r, 1) \uparrow$ & 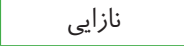 \\
\hline \multicolumn{4}{|c|}{ تعداد فرزندان } \\
\hline & & 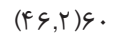 & . \\
\hline & & $(r q, r))_{\wedge}$ & 1 \\
\hline & & $(\mid \wedge, \Delta) Y F$ & r \\
\hline & & $(f, \xi) \xi$ & r \\
\hline & & $(1,0) r$ & r \\
\hline
\end{tabular}

جدول ا نشان مىدهد كه سن حدودا 91 درصد زنان متقاضى

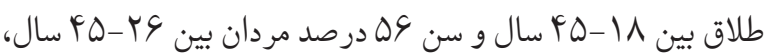

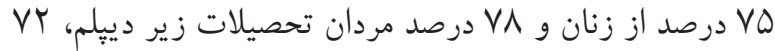
درصد زنان بيكار و بدون درآمد و هم درصد مردان شغل آزاد با در آمد متوسط | - ب ميليون تومان بودند. از بين متقاضيان طلاق، Tr درصد آنان سال اول زناشويىشان بود؛ rاه درصد ازدواج 9. آنها به شكل معرفى توسط دوستان و آشنايان، محل زندكى درصد آنها شهر بود. علت تقاضاى طلاق هس درصد مشكلات رفتارى (ضرب و شتم، دشنام گويى، بىتوجهى و بىاحترامى)، مشكلات جنسى F IV درصد و درصد اعتياد بودند. ازنظر تعداد

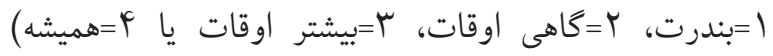
درجهبندىشده است. روايى و يايايى مقياس زوجى اينرج در يثزوهشهاى داخلى و خارجى مورد تأييد قراركرفته است (Y). در اين بثزوهش، ابتدا كليه نمونه ها فرم رضايتنامه را آكاهانه تكميل كردند. اطلاعات مندرج در يرسشنامهها محرمانه بود. در يايان هم نتايج بهصورت كلى منتشر شد و در اختيار نمونهها قرار كرفت.

دادههاى جمع آورىشده با استفاده از SPSS20 تحليل شدند. جهت تحليل دادها از ضريب كندال استفاده شد.

افافته

يافتههاى توصيفى: جدول ا. جدول توصيفى متغيرهاى جمعيتشناختى نمونه زوج

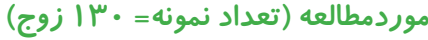

\begin{tabular}{|c|c|c|c|}
\hline مرد & زن - ان & زوج & متغير \\
\hline \multicolumn{4}{|c|}{ سن } \\
\hline$\cdot$ & $(9, r) \backslash r$ & & $<11$ \\
\hline$(r \xi, r) \mu r$ & $(r \mu, q) \varphi q$ & & $r \Delta-1 \Lambda$ \\
\hline$(\Delta \varphi, q) V F$ & $(r r, q) F F$ & & $r \Delta-r \varepsilon$ \\
\hline (1s)rr & $($ (YT) r. & & + ts \\
\hline \multicolumn{4}{|c|}{ تحصيلات } \\
\hline$(r \xi, q) \uparrow \wedge$ & $(\mathcal{F} F, G) \Delta \wedge$ & & ابتدائى \\
\hline$(\Psi \wedge, \Delta) \Delta \cdot$ & $\left(M^{\mu}, \Lambda\right) F F$ & & دييلم \\
\hline$(r), 0) r \wedge$ & $(\mid \wedge, \Delta) Y F$ & & كارشناسى \\
\hline$(r, 1) \mathcal{F}$ & $(r, 1) F$ & & بالاتر از كارشناسى \\
\hline \multicolumn{4}{|c|}{ 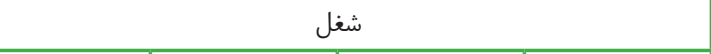 } \\
\hline$(\Delta \wedge, \Delta) \vee \varsigma$ & $(\xi, Y) \wedge$ & & آزاد \\
\hline$($ ( ৭, r) r人 & $(9, r) \backslash r$ & & كارمند \\
\hline$(\mid r, r) \mid \varepsilon$ & $(V Y, r) q F$ & & بى كار \\
\hline \multicolumn{4}{|c|}{ در آمد (ميليون تومان) } \\
\hline$(\mid \wedge, D) Y F$ & & & $<1$ \\
\hline$(\Delta \cdot,) \subseteq \varsigma$ & $(\mid r, r) \backslash G$ & & $r-1$ \\
\hline$(Y V, V)$ rs & $(r, 1) \mathcal{F}$ & & $+r$ \\
\hline$(r, 1) F$ & $(\wedge \uparrow, s) \|$. & & بدون درآمد \\
\hline \multicolumn{4}{|c|}{ طول مدت ازدواج (سال) } \\
\hline & & $(r r, \Delta) r q$ & 1 \\
\hline
\end{tabular}


مردان از رضايت زناشو يیى كمى برخوردار بودند. نيمى از زوجين

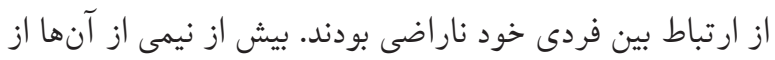

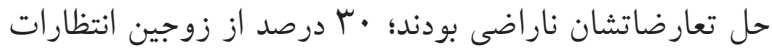

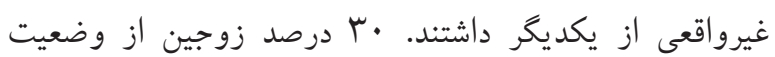

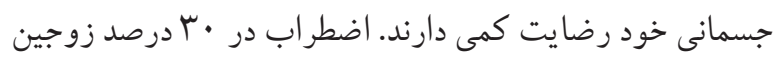

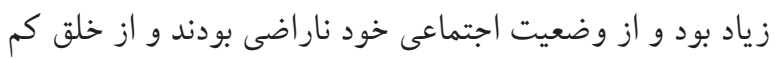

رنج مىبرند. يافتهای هاى تحليلى: فرضيه: بين رضايت زناشويى زوجين و عوامل جمعيتشناختى آنها رابطه وجود دارد. الف: بررسى رابطه بين رضايت زناشويى زنان و و عوامل جمعيتشناختى

جدول سّ. همبستخى بين رضايت زناشويى زنان و عوامل جمعيتشناختى (با استفاده از آزمون همبستخى كندال) رنال

\begin{tabular}{|c|c|c|c|c|c|c|}
\hline ازدواج & طول مدت & شغل & در آمد & تحصيلات & سن & \\
\hline$-\cdot / r T \Delta$ & r./.-. & $\cdot / \cdot \Delta V$ & .1111 &.$- / 199$ & 1 & ضمبستخى \\
\hline.$/ . r q$ & . IGYG & . / & . / $q$. &.$/ F \Delta$ &.$/ \ldots$ & p-value \\
\hline
\end{tabular}

نتايج جدول ץ نشان مىدهد كه بين سن زنان و رضايت

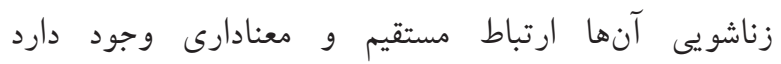

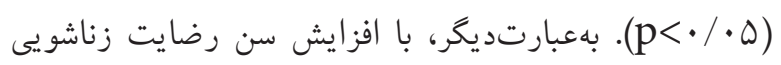

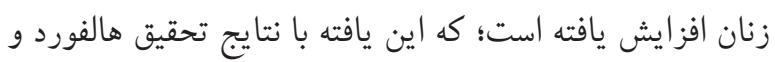

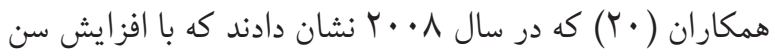
رضايت زناشويى زنان كاهش مى يابد همخوانى ندارد.

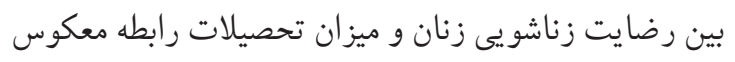

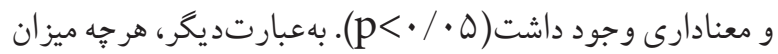
تحصيلات افزايش مى يافت، رضايتمندى زنان كاهش مى يافت.

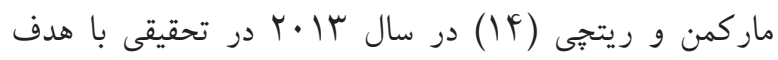
بررسى برنامه بيشخيرى وآموزشى رابطه ز زوجين بيش از ازدواج

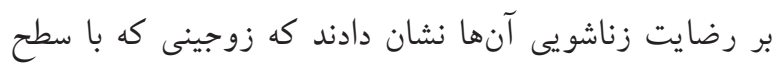
1. Prevention and Relationship Education Program(PREP)
فرزندان نيز • ب درصد از زوجين بدون فرزند بودند؛ كه در اين

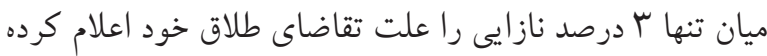
بودند.

جدول r. توصيف نمرات رضايتمندى زناشويى و خر دهمقياس هاى آن

\begin{tabular}{|c|c|c|c|}
\hline مرد & زن & سن & متغير \\
\hline$(\Delta \&, q) \vee F$ & $(\Delta \cdot, \Lambda) \subseteq \varsigma$ & $10-0$ & \multirow{3}{*}{ زاشايتمندى } \\
\hline$(F \cdot) \Delta r$ & $(\mathcal{F} F, \mathcal{G}) \Delta \wedge$ & $r \Delta-r$. & \\
\hline$(r, 1) \mathcal{F}$ & $(\mathcal{f}, \xi) \xi$ & s. $-F$. & \\
\hline 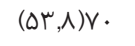 & $(\Delta \cdot, \wedge) \subseteq \hookrightarrow$ & $10-0$ & \multirow{3}{*}{ رضايت از ارتباط } \\
\hline$(F, \mid 1) \Delta G$ & $(F q, r) \subseteq F$ & $r \Delta-r$. & \\
\hline$(r, 1) \uparrow$ & . & $s \cdot-r$. & \\
\hline$(\varsigma \vee, \vee) \wedge \wedge$ & $(\Delta \Delta, r) \vee r$ & $10-0$ & \multirow{3}{*}{ رضعايت از حل } \\
\hline$(\mu \cdot, \Lambda) \varphi^{f}$. & $\left(\mathcal{F}^{\mu}, 1\right) \Delta \mathcal{G}$ & $r \Delta-r$. & \\
\hline$(\Lambda, \tilde{r}) \Gamma$ & $(\Lambda, \tilde{r}) \Gamma$ & $s \cdot-r$. & \\
\hline$(1, \Delta 9) r$ & $(r, \cdot \Delta))^{\mu}$ & $10-\Delta$ & \multirow{3}{*}{ تحريف آرمانى } \\
\hline$(\Delta \mu, \Lambda) \vee \cdot$ & $(\Delta \cdot, \wedge) \subseteq \varsigma$ & $r \Delta-r$. & \\
\hline$(F F, \xi) \Delta \Lambda$ & 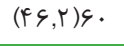 & $G \cdot-r$. & \\
\hline$(\mu, \mu, \Lambda) F F$ & $(F \cdot) \Delta r$ & $c_{-}$. & \multirow{4}{*}{ رضايت از وضعيت } \\
\hline$(\mathcal{F} \varepsilon, r) \xi$. & $(\mathcal{F}, 1) \Delta G$ & $11-V$ & \\
\hline$(1 \varepsilon, 9) r r$ & $(\mid r, \wedge) \backslash \wedge$ & $19-1 \mid$ & \\
\hline$(r, 1) q$ & $(r, 1) q$ & $r 1-1 V$ & \\
\hline$(r \digamma, \zeta) r r$ & 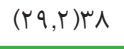 & $s_{-} \cdot$ & \\
\hline$(\Delta \varsigma, 9) \vee F$ & $(\Delta r, r) \& \Lambda$ & $11-V$ & \multirow{3}{*}{ ميزان اضطراب } \\
\hline$(\mid \Delta, r) r$. & $(1 \wedge, \Delta) Y F$ & $19-11$ & \\
\hline$\cdot$ & $\cdot$ & rI-IV & \\
\hline$(\mathcal{F}, V) \subseteq Y$ & $(F \mathcal{F}, \mathcal{G}) \Delta \wedge$ & $r r_{-}$. & \multirow{3}{*}{ رضايت از وضعيت } \\
\hline$(F \vee, V) \& Y$ & $(\mathcal{q} q, \bar{Y}) \mathcal{F}$ & $F \cdot-r \mu$ & \\
\hline$(\mathcal{F}, \mathcal{G}) \mathcal{G}$ & $(\xi, \Gamma) \wedge$ & G. $-F_{1}$ & \\
\hline$(r F, \xi \mid) r r$ & $(r \Delta, F) \& \varphi$ & $\varphi_{-}$. & \multirow{4}{*}{ افسردگى } \\
\hline$(\varsigma), \Delta) \wedge$. & $(\Delta \Delta, r) \vee r$ & $11-V$ & \\
\hline$(\mid r, \wedge) \backslash \wedge$ & $(9, r) \backslash r$ & $19-11$ & \\
\hline$\cdot$ & $\cdot$ & $r I-I V$ & \\
\hline 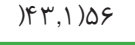 & $(\Delta \wedge, \Delta) \vee \varsigma$ & $r r_{-} \cdot$ & \multirow{3}{*}{ سلامت عمومى } \\
\hline$(\Delta r, \Gamma) \& \wedge$ & $(F \cdot) \Delta r$ & $r \cdot-r \mu$ & \\
\hline$(\mathcal{F}, \mathcal{G}) \mathcal{G}$ & $(1,0) r$ & $G \cdot-q_{1}$ & \\
\hline
\end{tabular}

جدول ب اين نتايج را نشان مىدهد: بيش از • له درصد زنان و 
زناشويى مردان و ميزان تحصيلات رابطه معكوس و معنادارى

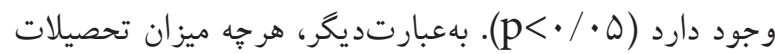

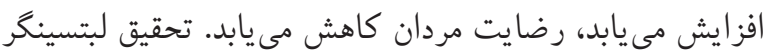

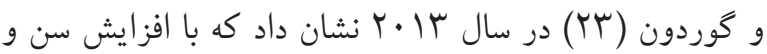
ميزان تحصيلات رضايتمندى كاهش مى يابد.

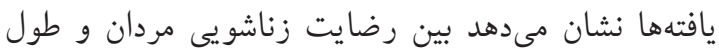

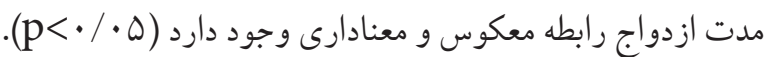

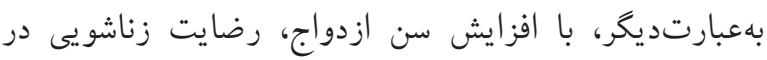

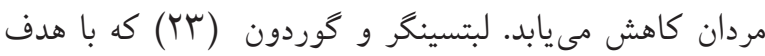
بررسى تأثير عوامل جمعيتشناختى بر زوجين انجام داده بودند، مؤ يد اين مسئله است كه با افزايش سن، رضايت زناشو يكى مردان

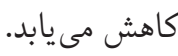

همجنين بين در آمد، شغل و نوع ازدواج و رضايت زناشويى

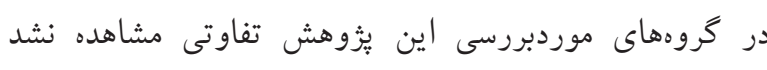

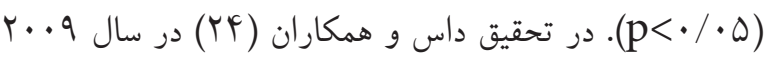

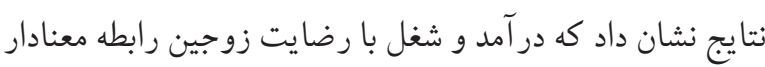
و مستقيم دارد؛ كه اين با نتيجه تحقيق حاضر همخوانى ندارد. لذا بايد تأثير عوامل فرهنگى رادر دآن آن بررسى كرد.

بحث هدف اين يُوهش بررسى رابطه عوامل جمعيتشناختى و رضايت

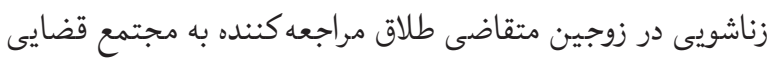

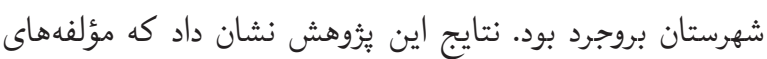

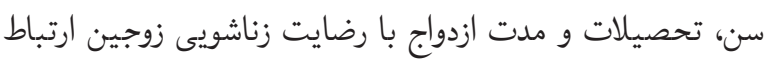
معنادارى دارد و رابطه سن و رضايت زناشويى بهصورت مستقيم و معنادار بوده ولى ارتباط ميان ميزان تحصيلات و مدت ازدواج

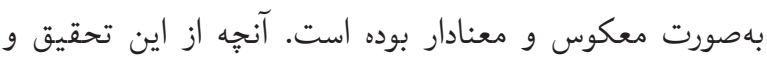

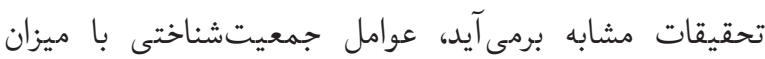

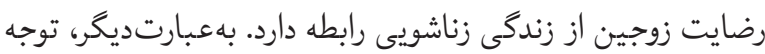

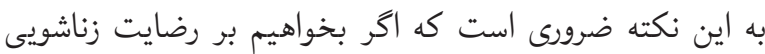

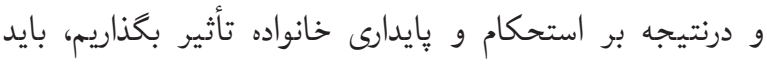

آكاهى بيشترى در جلسات توانمندسازى شركت كرده بودند، حساسيت بيشترى در زمينه مسائل ارتباطى همسرشان نشان داده

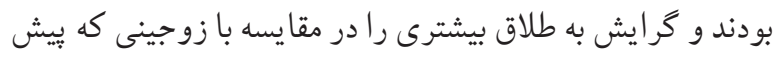

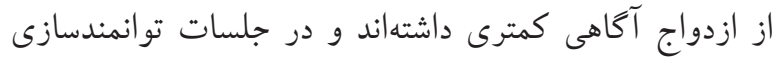

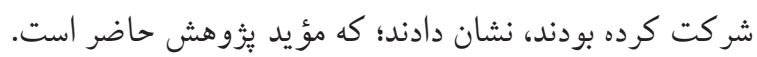

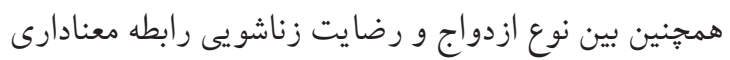
وجود داشت (ه • p p)؛ به گونهاى كه در ازدواجهاى فاميلى و معرفى در مقايسه با نوعدوستى رضايتمندى كمترى كزارش شده بود. نتايج تحقيق حاضر نشان داد كه بين ميزان در آمد و نوع شغل و طول مدت ازدواج با رضايت زناشويى رابطهاى وجود ندارد

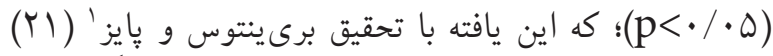

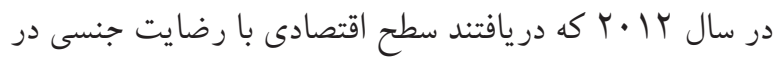
زنان مرتبط است و با تحقيق يانگ جى بو و همكاران (Y (Y) در سال

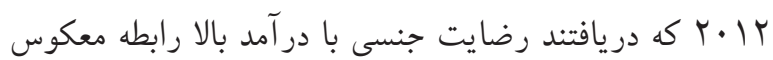

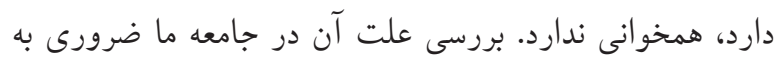
نظر مىرسد. ب: بررسى رابطه بين رضايت زناشويى مردان و عوامل جمعيتشناختى جدول ع. همبستخى بين رضايت زناشويى مردان و عوامل

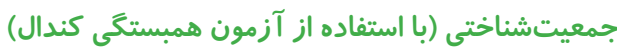

\begin{tabular}{|c|c|c|c|c|c|c|}
\hline ازدواج & طول مداج & شغل & در آمد & تحصيلات & سن & \\
\hline.$/ .9 r$ &.$- /|f|$ &.$- / .9 Y$ &.$-|\cdot q|$ &.$- / T F Y$ & $-1 / \ldots$ & ضريستخى \\
\hline .1090 &.$/ \varphi_{\Lambda}$ &.$/ 09 F$ & - /VYS & . ru &.$/ \ldots$ & p-value \\
\hline
\end{tabular}

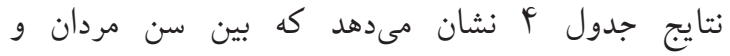
رضايت زناشويى آنها ارتباط معنادار و معكوس وجود دارد

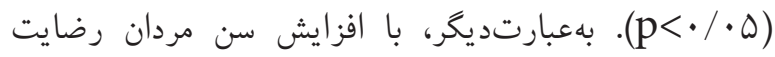

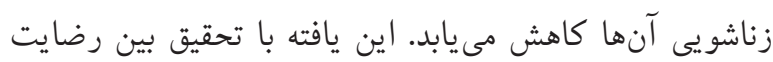

1. Barrientos \& Páez 


$$
\begin{aligned}
& \text { در يُوهششاى آتى بررسى شوند. } \\
& \text { سباسگُز ارى }
\end{aligned}
$$

اين مقاله حاصل پاياننامه دكترى گروه آموزش بهداشت و ارتقاء

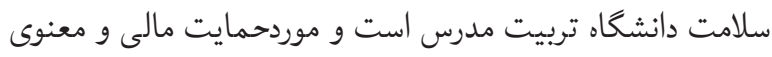

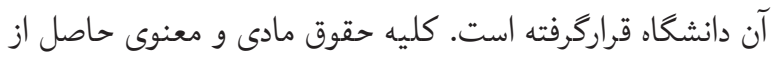

آن به دانشخاه تربيت مدرس تعلق دارد.

\section{References:}

1. Goldenberg, H. and I. Goldenberg (2012). Family therapy: An overview, Cengage Learning.

2. Killinger, K. A., et al. (2014). "Exploring Factors Associated With Sexual Activity in Community-Dwelling Older Adults." Research in gerontological nursing 7(6): 256-263.

3. Amato, P. R. (1996). "Explaining the intergenerational transmission of divorce." Journal of Marriage and the Family: 628-640.

4. Markman, H. J., et al. (2013). "A randomized clinical trial of the effectiveness of premarital intervention: Moderators of divorce outcomes." Journal of Family Psychology 27(1): 165.

5. Halford, W. K., et al. (2015). "The Gap Between Couple Therapy Research Efficacy and Practice Effectiveness." Journal of marital and family therapy.

6. Jamali, S., et al. (2014). "The relationship between body mass index and sexual function in infertile women: $A$ cross-sectional survey." Iranian journal of reproductive medicine 12(3): 189.

7. Halford, W. K., et al. (2015). Couple Communication. Clinical Guide to Helping New Parents, Springer: 39-57.

8.Watson, D., et al. (2000). "General traits of personality and affectivity as predictors of satisfaction in intimate relationships: Evidence from self-and partner-ratings." Journal of personality 68(3): 413-449.

9. Gattis, K. S., et al. (2000). "Birds of a feather or strange birds? Ties among personality dimensions, similarity, and marital quality." Journal of Family Psychology 18 (4):564.

10. Javanmard, G. H. and R. M. Garegozlo (2013). "The Study of Relationship Between Marital Satisfaction and Personality Characteristics In Iranian Families." Procedia-Social and Behavioral Sciences 84: 396-399.

11. Yoo, H., et al. (2014). "Couple communication, emotional and sexual intimacy, and relationship satisfaction." Journal of Sex \& Marital Therapy 40(4):257-293.

12. Khadivzadeh, T., et al. (2016). "The Effect of Interactive Educational Workshops with or Without Standardized Patients on the Self-Efficacy of Midwifery Students in Sexual Health Counseling." Journal of Midwifery and Reproductive Health 4(2): 562-570.

$$
\begin{aligned}
& \text { برنامهاى توانمندسازى و غنىسازى را با توجه به ويثزىهاى } \\
& \text { محيطى، جمعيتشناختى زوجين، طراحى و تدوين نماييم. } \\
& \text { نتيجه كيرى: با توجه به ميزان رضايت زناشويى و متغيرهاى } \\
& \text { بررسى شده در اين يزوهش و اهميت مسئله رضايت زناشويى در } \\
& \text { بايدارى خانواده، بيشنهاد مى شود كه رابطه ساير عوامل مؤثر بر } \\
& \text { اين مسئله مثل عوامل فرهنكى، مذهبى، روابط يِيش از ازدواج، }
\end{aligned}
$$

13. Mohr, W. K. (2006). Psychiatric-mental health nursing, Lippincott Williams \& Wilkins.

14. Markman, H. J. and L. L. Ritchie (2015). "Couples relationship education and couples therapy: healthy marriage or strange bedfellows?" Family process 54(4): 655-671.

15. Waite, L. J., et al. (2009). "Marital happiness and marital stability: Consequences for psychological well-being." Social Science Research 38(!): 201-212.

16. Fowers, B. J. and D. H. Olson (1989). "ENRICH Marital Inventory: A discriminant validity and cross-validation assessment." Journal of marital and family therapy 15(1): 65-79.

17. Jamali, S., et al. (2014). "Sexual function in fertile and infertile women referring to the Jahrom Infertility in 2011." women's health 4: 5.

18. Rosen-Grandon, J. R., et al. (2004). "The relationship between marital characteristics, marital interaction processes, and marital satisfaction." Journal of Counseling \& Development 82(1): 58-68.

19. Madathil, J. and J. M. Benshoff (2008). "Importance of marital characteristics and marital satisfaction: A comparison of Asian Indians in arranged marriages and Americans in marriages of choice." The Family Journal 16(3): 222-230.

20. Halford, W. K., et al. (2008). "Strengthening couples' relationships with education: Social policy and public health perspectives." Journal of Family Psychology 22(4): 497.

21. Barrientos, J. E. and D. Páez (2006). "Psychosocial variables of sexual satisfaction in Chile." Journal of Sex \& Marital Therapy 32(5): 351-368.

22. Young, J. L. (2012). Chinese-American Transnational Marriage: Cultural Differences and Marital Satisfaction, The Ohio State University.

23. Litzinger, S. and K. C. Gordon (2005). "Exploring relationships among communication, sexual satisfaction, and marital satisfaction." Journal of Sex \& Marital Therapy 31(5): 409-424.

24. Doss, B. D., et al. (2009). "The effect of the transition to parenthood on relationship quality: an 8-year prospective study." Journal of personality and social psychology 96(3): 601. 